УДК $631.45+635.8$

DOI: 10.36461/NP.2019.52.3.003

\title{
ИЗУЧЕНИЕ ВОЗМОЖНОСТИ ИСПОЛЬЗОВАНИЯ ОТХОДОВ ГРИБОВОДСТВА В БИОРЕМЕДИАЦИИ ПОЧВ СЕЛЬСКОХОЗЯЙСТВЕННОГО НАЗНАЧЕНИЯ
}

\author{
Г. В. Ильина, доктор биол. наук, профрессор; С. А. Сашенкова, канд. биол. наук, доцент; \\ Д. Ю. Ильин, канд. биол. наук, дочент
}

\begin{abstract}
Федеральное государственное бюджетное образовательное учреждение высшего образования «Пензенский государственный аграрный университет», Россия, т. (8412) 62-81-51, e-mail: g-ilyina@yandex.ru
\end{abstract}

В работе рассматриваются возможности использования органических субстратов после культивирования на них мицелиальных культур ксилотрофных базидиомицетов для биоремедиации почв, загрязненных полифенольными соединениями и тяжелыми металлами. Показано снижение в 0,9-3 раза показателя интегральной токсичности почв под действием мицелиально-субстратных комплексов (отходов грибоводства и биотехнологий). Изучена динамика содержания гумуса в почвенных образцах в результате внесения в качестве удобрения отходов производства вешенки устричной (Pleurotus ostreatus). Установлено, что содержание гумуса в опытных вариантах увеличилось на 0,08-0,14 \%. При этом использование отходов грибоводства в качестве удобрений позволило повысить урожайность яровой пшеницы «Тулайковская 10» на 10,7-29,5 \%.

Ключевые слова: биоремедиация почв, ксилотрофные базидиомицеты, мицелиальные культуры, отходы грибоводства, интегральная токсичность.

\section{Введение}

Почва - важнейший природный ресурс, обеспечивающий существование биосферы и человека как ее части. Ничто не может заменить почвенный покров, который создавался миллионы лет. Вместе с тем, в результате хозяйственной деятельности разрушение почвы, снижение ее плодородия и загрязнение приобретают глобальные масштабы. Так, источником загрязнений сельскохозяйственных угодий являются минеральные удобрения, ядохимикаты, некоторые из которых содержат в своём составе фенольные, хлорорганические соединения, ртуть и другие тяжёлые металлы, которые накапливаются в почве, ухудшая ее качество. Поэтому восстановлению продуктивности нарушенных земель и улучшению условий окружающей среды уделяется особое внимание, что находит подтверждение в большом количестве литературных источников, посвященных этой проблеме [3, 6, 12].

Одним из эфффективных методов, позволяющих восстановить почвенное плодородие и снизить уровень загрязнения, является биоремедиация. Использование для этих целей биологических технологий является более предпочтительным вследствие своей экологической безопасности, достаточно высокой эффективности и низкой себестоимости. Поэтому разработка и внедрение в практику сельского хозяйства технологий биоремедиации почв, загряз- ненных токсичными химическими веществами является актуальным направлением исследований $[12,13]$.

В литературе рассматриваются два основных подхода к биоремедиации почв с помощью микроорганизмов: биостимуляция - с использованием аборигенной микрофрлоры на территории, подвергшейся загрязнению, и биодополнение - с внесением в почву биопрепаратов микроорганизмов способных к деградации загрязнителя [12].

Ксилотрофные базидиомицеты, обладая богатым комплексом неспецифических ферментов - полифенолокидаз, способны разрушать поллютанты фенольной природы, в том числе их хлорированные производные [16]. Ферментативную активность этих грибов используют для очистки почвы от разливов нефти, в промышленности для отбеливания лигнинсодержащих материалов. Кроме того, поверхность мицелия, благодаря структуре хитина, входящего в состав клеточных оболочек, способна сорбировать соединения тяжелых металлов [7]. Поэтому проведение исследований по использованию ксилотрофных грибов для улучшения структуры почв является целесообразным и актуальным направлением как в теоретическом, так и прикладном аспектах.

Кроме того, при культивировании грибов в грибоводстве и биотехнологиях образуются отходы (отработанный субстрат с 
мицелием), которые можно было бы использовать в качестве биодополнения для санирования загрязненных почв и поддержания их плодородия. Например, только в Пензенской области ежегодно образуется, по разным данным, от 60 до 100 тонн отходов грибного производства.

Целью настоящей работы была оценка возможности использования отходов грибного производства - отработанного мицелия ксилотрофных грибов в качестве биоремедианта антропогенно нарушенных почв в пределах Пензенской области.

В ходе проведения исследований решались следующие задачи:

- изучить интегральную токсичность почв в местах, подвергшихся выраженному вариативному антропогенному воздействию, в частности, загрязнению тяжелыми металлами и галогенированными фенольными соединениями;

- отобрать виды и штаммы ксилотрофных базидиомицетов, обладающих максимальным ферментным потенциалом;

- изучить деструктивный, в отношении ксенобиотиков, потенциал ферментативных комплексов, имеющихся в коллекции штаммов видов грибов - ксилотрофов, перспективных в грибоводстве;

- с использованием маркерного соединения изучить динамику содержания фенольного вещества в модельных субстратах под воздействием ферментов мицелия;

- изучить динамику интегральной ток-
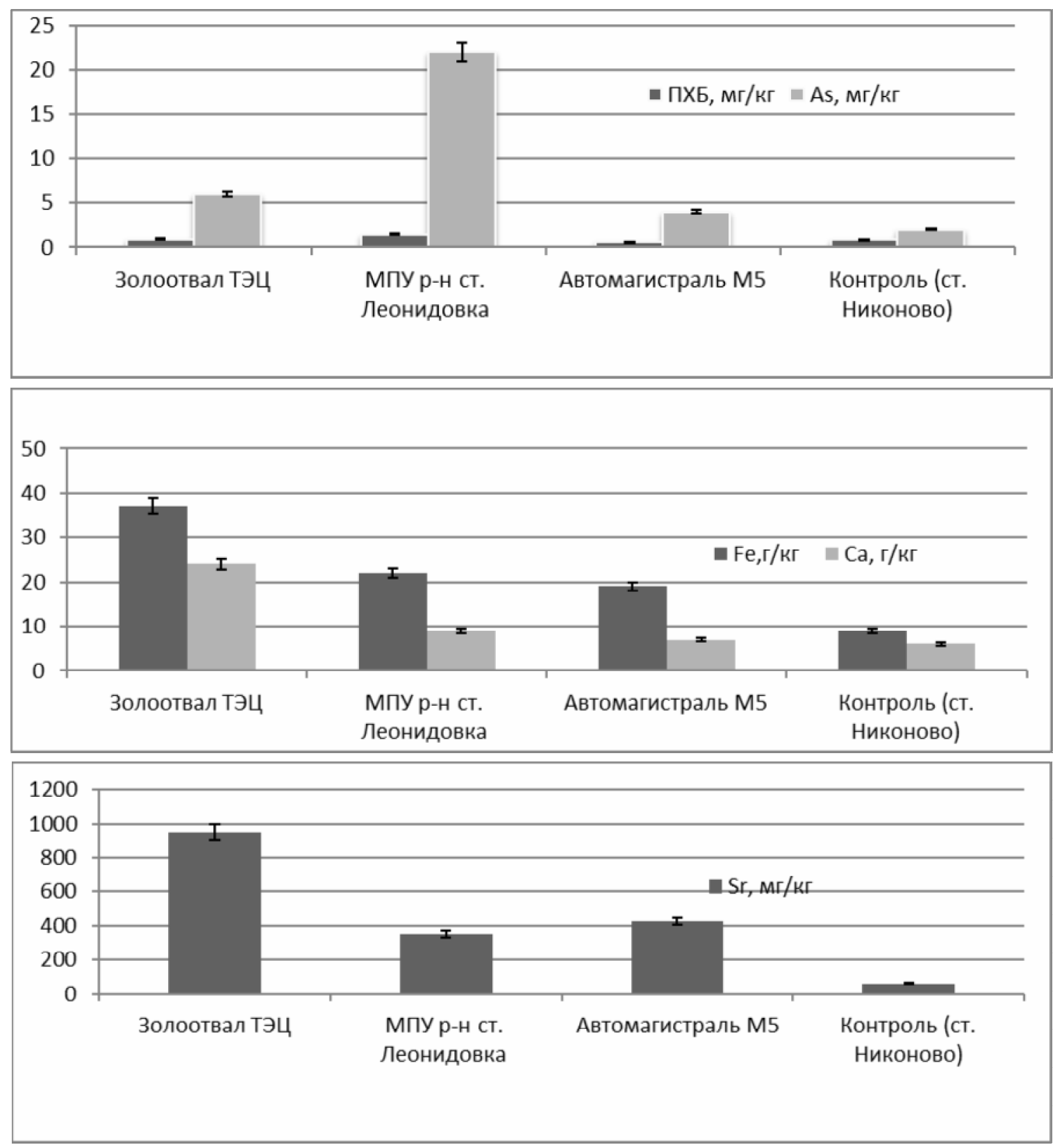

Puc. 1. Содержание поллютантов в отобранных почвенных образцах $p>0,05$, планки погрешностей - ошибка средней

\begin{tabular}{l|l} 
Нива Поволжья & № 4 (53) ноябрь 2019
\end{tabular} 
Оценка токсичности вытяжек из отобранных образцов

\begin{tabular}{|c|c|c|c|}
\hline \multirow{2}{*}{$\begin{array}{l}\text { Место взятия } \\
\text { пробы почвы }\end{array}$} & \multicolumn{2}{|c|}{ Тест-объект (методика) } & \multirow{2}{*}{$\begin{array}{c}\text { Оценка } \\
\text { тестируемой пробы }\end{array}$} \\
\hline & Daphnia magna & Escherichia coli & \\
\hline Золоотвал ТЭЦ & 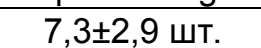 & $61,2 \pm 0,3$ y. e. & \multirow{3}{*}{$\begin{array}{l}\text { Оказывает острое токси- } \\
\text { ческое действие. Проба } \\
\text { сильно токсична }\end{array}$} \\
\hline МПУ р-н ст. Леонидовка & 8,7士3,5 шт. & $65,3 \pm 12,9$ y. e. & \\
\hline Автомагистраль М5 & 8,3 $\pm 3,3$ шт. & $61,2 \pm 0,3$ y. e. & \\
\hline Ст. Никоново & 2,3 $\pm 0,8$ шт. & $4,5 \pm 0,3$ у. е. & Проба не токсична \\
\hline
\end{tabular}

сичности антропогенно нарушенных почв под воздействием используемого отхода отработанного мицелиально-субстратного комплекса ксилотрофных грибов;

- изучить влияние внесения отходов грибоводства на почвенное плодородие и урожайность яровой пшеницы «Тулайковская 10».

\section{Методы и материалы}

Изучение влияния антропогенной деятельности предполагало оценку интегральной токсичности почв на загрязненных территориях. Были отобраны образцы почвы [2] на следующих территориях Пензенской области:

- лесное сообщество, сформированное на золоотвале ТЭЦ г. Пенза;

- место прежнего уничтожения химического оружия в окрестностях ст. Леонидовка Пензенского района (МПУ);

- лесополоса, расположенная вдоль оживленной автомагистрали М5 «Москва-Самара» (в пределах 30 м от дорожного полотна);

- лесной массив близ ст. Никоново Городищенского района (контроль).

Предварительно был проведен химический анализ почв с помощью метода хроматографии. При проведении исследования использовались методики определения токсичности почв с помощью биотестирования, включенные в Федеральный реестр [10]. При этом использовались тест-объекты Escherichia coli и Daphnia magna из соответствующих методик: ПНД Ф Т 16.1:2.3:3.8-04; ПНД Ф Т 14.1:2:3:4.11-04 и ФР.1.39.2007. 03222, ПНД Ф Т 14.1:2:4.12-06 [8, 9].
На следующем этапе были отобраны виды грибов, обладающие не только полифенолокидазной активностью, но и распространенные в культуре по причине перспективности в биотехнологии [5, 15]. Вешенка Pleurotus ostreatus - лидер среди культивируемых съедобных грибов, в мире накапливается огромное количество мицелия на органическом субстрате - отходов ее производства. Трутовик лакированный Ganoderma lucidum - мировой лидер среди лекарственных грибов, траметес разноцветный Trametes versicolor культивируют в качестве продуцента биологически активных веществ, на основе которых создан препарат - трамелан [14, 15]. Из множества штаммов этих видов в результате длительного скрининга отобраны культуры с максимальной ферментативной активностью, которые и стали объектами исследований.

Культуры выращивали на лигноцеллюлозных субстратах, а после полного обрастания вносили мицелиально-субстратный комплекс в образцы испытуемых почв из расчета 20 г/кг почвы. Далее образцы выдерживали в модельных условиях в течение 1,5 лет, причем каждые полгода проводили оценку интегральной токсичности [10].

Показатель интегральной токсичности, по которому можно судить о степени нарушенности почвы получали путем биотестирования образцов. Это быстрый воспроизводимый способ, не требующий химического анализа, но дающий представление об опасности таких почв [1].

Для подтверждения нашего предполо-

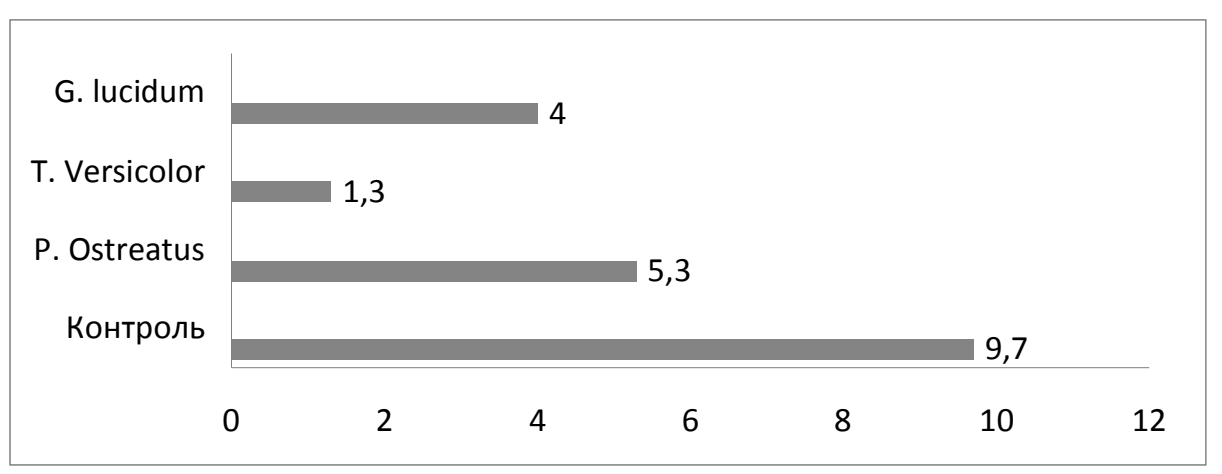

Puc. 2. Содержание 2,4 дихлорфеноксиуксусной кислоты в модельных субстратах (ма/ка) под воздействием ферментов мицелия после 12 месяцев культивирования 
Влияние отходов грибного производства на содержание гумуса в почве, \%

\begin{tabular}{|l|c|c|c|c|}
\hline \multirow{2}{*}{ Вариант опыта } & \multicolumn{4}{|c|}{ Содержание гумуса } \\
\cline { 2 - 5 } & $\begin{array}{c}\text { Исходное } \\
\text { значение }\end{array}$ & $\begin{array}{c}\text { Первый } \\
\text { год }\end{array}$ & $\begin{array}{c}\text { Второй } \\
\text { год }\end{array}$ & $\begin{array}{c}\text { Третий } \\
\text { год }\end{array}$ \\
\hline Контроль (без удобрений) & 2,60 & 2,60 & 2,59 & 2,58 \\
\hline Внесение отходов грибного производства 4 т/га & 2,62 & 2,71 & 2,73 & 2,70 \\
\hline Внесение отходов грибного производства 5 т/га & 2,59 & 2,70 & 2,72 & 2,69 \\
\hline Внесение отходов грибного производства 6 т/га & 2,61 & 2,72 & 2,75 & 2,73 \\
\hline НСР $_{05}$ ед. & 0,06 & 0,03 & 0,05 & 0,04 \\
\hline
\end{tabular}

жения о том, что причиной снижения интегральной токсичности служит именно деструкция галогенизированных полифенолов ферментами мицелия параллельно был проведен модельный опыт. С использованием маркерного соединения (2,4 дихлорфеноксиуксусная кислота) изучена динамика содержания этого вещества в модельных субстратах под воздействием ферментов мицелия. Это вещество применяется в качестве гербицида. Для этого вносили в стерильные питательные субстраты грибов 2,4 Д в количестве 10 мг/кг сухого субстрата в расчете на действующее вещество. Затем ежемесячно, по мере развития мицелия, отмечали динамику содержания модельного токсиканта в субстрате. Контроль представлял собой стерильный субстрат, в который не вносили культуру гриба, но добавили аналогичную концентрацию модельного соединения.

С использованием отходов грибного производства ООО «Ботаник», расположенного в р. п. Лунино Пензенской области, которые представляют собой соломенную резку, частично ферментированную мицелием гриба вешенки, был проведен полевой опыт по следующей схеме:

1. Без удобрений (контроль);

2. Отход грибного производства 4 т/га (эквивалентный 12 т/га навоза по углероду);

3. Отход грибного производства 5 т/га (эквивалентный 15 т/га навоза по углероду);
4. Отход грибного производства 6 т/га (эквивалентный 18 т/га навоза по углероду);

Площадь делянки 5 м², повторность опыта четырехкратная, варианты в опыте размещены методом рендомизированных повторений [4]. На делянках выращивалась яровая пшеница «Тулайковская 10».

Почва в районе опыта серая лесная суглинистая, содержание гумуса не превышает 2,6 \%, что соответствует характеристикам почв такого типа [11].

\section{Результать}

Хроматографическое исследование отобранных образцов почв выявило присутствие галогенизированных полихлорфенолов во всех изученных образцах почв, но в разных количествах. Максимальная концентрация обнаружена в образце почвы, отобранной близ ст. Леонидовка. Этот же образец содержал повышенную концентрацию мышьяка 4,5 мг/кг при ПДК в почве до 2 мг/кг (рис.1).

Такое состояние объясняется тем, что в этом районе начиная с 1950 годов, производилось уничтожение трофейного химического оружия путем его химической дезактивации с применением хлорсодержащих агентов (отсюда галогенизация). Сами же фенолы широко распространены в лесной почве и являются результатом жизнедеятельности растений. По содержанию других поллютантов лидировал образец с золоотвала ТЭЦ (рис. 1).

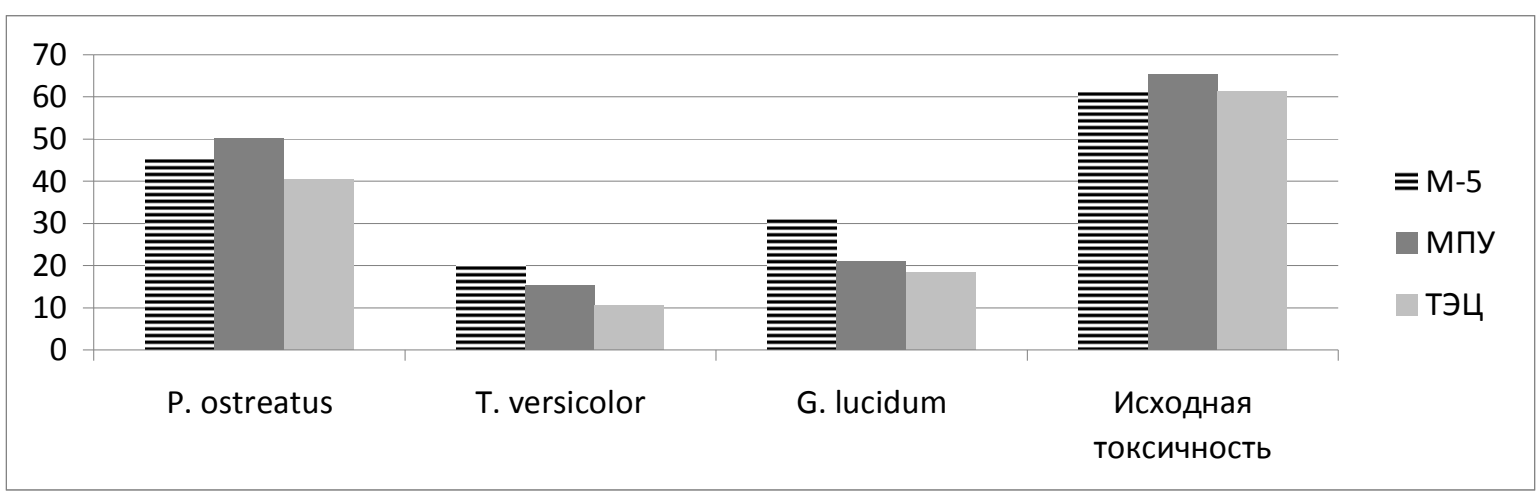

Pис. 3. Снижение интегральной токсичности образцов почв при внесении мицелиально-субстратных комплексов грибов 
Влияние отходов грибного производства на урожайность яровой пшеницы «Тулайковская 10»

\begin{tabular}{|l|c|c|c|}
\hline \multicolumn{1}{|c|}{ Вариант опыта } & Урожайность, & Отклонение от контроля \\
\cline { 3 - 4 } & т/га & т/га & $\%$ \\
\hline Без удобрений (контроль) & 2,34 & - & - \\
\hline Внесение отходов грибного производства 4 т/га & 2,59 & 0,25 & 10,7 \\
\hline Внесение отходов грибного производства 5 т/га & 2,87 & 0,53 & 22,6 \\
\hline Внесение отходов грибного производства 6 т/га $^{*}$ & 3,03 & 0,69 & 29,5 \\
\hline $\mathrm{HCP}_{05}$, т/га & 0,16 & - & - \\
\hline
\end{tabular}

Bce разнообразие поллютантов определило токсичность - интегральный показатель степени нарушенности почвы. Полученные результаты, представленные в таблице 1, свидетельствуют, что вытяжки из всех почвенных образцов, кроме контроля, оказывают острое токсическое действие на тест-объекты.

С помощью длительного культивирования мицелия отобранных для эксперимента штаммов ксилотрофных базидиомицетов на субстратах с использованием маркерного соединения (2,4 дихлорфеноксиуксусной кислоты) установлено, что все штаммы достоверно снижают содержание маркерного соединения в субстрате. Причем наибольшую активность проявил штамм траметеса разноцветного (T. versicolor) (рис. 2). Это коррелирует с обнаруженной у данного штамма наиболее выраженной, чем у других изученных культур, полифенолоксидазной активностью [5].

Нами установлено постепенное снижение интегральной токсичности образцов почв при внесении в них мицелиальносубстратных комплексов грибов при помощи тест-объекта Escherichia coli. Отмечено снижение токсичности под действием всех изученных культур, однако наибольшую активность в плане ремедиации вновь проявил штамм траметеса разноцветного (T. versicolor) (рис. 3).

Учитывая большие объемы отработанного субстрата вешенки, образующиеся в грибоводстве, следует отметить, что используемый штамм ( $P$. ostreatus) можно рассматривать в качестве биоремедианта, так как отмечено достоверное снижение токсичности, хотя и менее интенсивное по сравнению с другими исследуемыми видами ксилотрофных базидиомицетов (рис. 3).

В состав мицелиально-субстратного комплекса, помимо ферментативно активного и сорбирующего поллютанты мицелия, входит непосредственно, масса соломы, также содержащая питательные компоненты и способная улучшить структуру почвы и повышать ее плодородие. Так как в соломе содержится около 95 \% органиче- ского вещества, ценного для повышения плодородия, и с пятью тоннами соломы возвращается 20-25 кг азота, 5-7 кг фосфора, 60- 90 кг калия [11].

Изучая динамику содержания гумуса, в экспериментальные образцы почвы в качестве биоремедианта внесли мицелиальносубстратный комплекс - отход после выращивания вешенки устричной. Использование данного вида объясняется тем, что в практическом смысле воспроизведение такого приема ремедиации в естественных условиях могут обеспечить только объемы отходов гриба, который широко культивируется в промышленных условиях.

Результаты трехлетнего полевого опыта показывают, что содержание гумуса в почвах без внесения удобрений, существенно не изменяясь, имеет тенденцию к снижению, тогда как использование отходов грибоводства в качестве удобрений позволяет поддерживать и несколько увеличивать на 0,08-0,14 \% содержание гумуса в почве (табл. 2).

Внесение удобрения в виде отхода грибного производства способствовало достоверному повышению урожайности яровой пшеницы (табл. 3). Максимальная урожайность наблюдалась в варианте с нормой 6 т/га, где она составила 3,03 т/га, что выше, чем на контроле, на 0,69 т/га или 29,5 \%.

\section{Заключение}

Мицелиально-субстратные органические комплексы - отходы производства грибов ксилотрофов - при внесении их в почвы, характеризующиеся повышенной интегральной токсичностью, достоверно снижают данные показатели. В качестве биоремедианта почв, загрязненных полифенольными соединениями можно рекомендавать отходы культивирования вешенки устричной Pleurotus ostreatus.

Отходы производства лекарственных грибов траметеса разноцветного Trametes versicolor и трутовика лакированного Ganoderma lucidum также могут быть перспективными в плане биоремедиации при наличии такого производства и достаточного количества образующихся отходов. 
Кроме того использование органических отходов грибного производства позволяет улучшить структуру почвы, позитивно влияя на содержание гумуса в её пахотном слое. Установлено достоверное повышение урожайности яровой пшеницы «Тулайковская 10» при внесении отходов грибоводства в качестве удобрений. Наибольший эфффект получен на варианте с нормой внесения отходов 6 т/га.

Таким образом, использование отходов грибного производства обеспечивает как природоохранный эфрфект в плане биоремедиации загрязненных почв сельскохозяйственного назначения, так и агрономиический - в плане поддержания почвенного плодородия и повышения урожайности сельскохозяйственных культур.

\section{Литература}

1. Биологический контроль окружающей среды: биоиндикация и биотестирование: учебное пособие для студ. высш. учеб. заведений / О. П Мелехова, Е. И. Сарапульцева, Т. И. Евсеева [и др.]- 3-е изд. - Москва: Академия, 2010. - 288 с.

2. ГОСТ 28168-89. Почвы. Отбор проб. [Электронный ресурc] URL: http://docs. cntd. ru/document/gost-28168-89 (дата обращения 26.09.19)

3. Домрачева, Л.И. Использование организмов и биосистем в ремедиации территорий / Л. И. Домрачева // Теоретическая и прикладная экология. - 2009 - № 4. - С. 4-16.

4. Доспехов, Б. А. Методика полевого опыта / Б. А. Доспехов. - Москва: Агропромиздат, 1985. $-351 \mathrm{c}$

5. Даниляк, Н.И. Ферментные системы высших базидиомецетов / Н.И. Даниляк, В. Д. Семичаевский, Л. Г. Дудченко. - Киев: Наукова думка, 1989. - 279 с.

6. Качмазов, Д. Г. Биоремедиация загрязненный почв / Д. Г. Качмазов // Международный научно-исследовательский журнал. - 2017 - № 12 (66), - 3. - С. 107-109. [Электронный ресурс] URL: https://research-journal. org/agriculture (дата обращения 26.09.19)

7. Куликова, Н. А. Использование базидиальных грибов в технологиях переработки и утилизации техногенных отходов: фундаментальные и прикладные аспекты (обзор) / Н. А. Куликова, О. И. Кляйн, Е. В. Степанова, И. В. Королева // Прикладная биохимия и микробиология. - 2011. Т. 47. № 6. - С. 619-634.

8. ПНД Ф Т 16.1:2.3:3.8-04. Количественный химический анализ почв. [Электронный ресурс] URL: http://docs. cntd. ru/document/1200082146 (дата обращения 26.09.19)

9. ПНД Ф Т 14.1:2:3:4.11-04. Токсикологические методы анализа. [Электронный ресурс] URL: https://files. stroyinf. ru/Data2/1/4293767/4293767837 htm (дата обращения 26.09.19)

10. ФР.1.39.2007.03222, ПНД Ф Т 14.1:2:4.12-06. Биологические методы контроля. [Электронный ресурc] URL: https://files. stroyinf. ru/Data2/1/4293842/4293842234. htm (дата обращения 26.09.19)

11. Швецова, Л. К. Гумусное состояние и азотный фонд основных типов почв при длительном применении удобрений: автореферат диссертации доктора биологических наук / Л. К. Швецова. - Москва, $1988-48$ с.

12. Янкевич, М. И. Биоремедиация почв: вчера, сегодня, завтра / М. И. Янкевич, В. В Хадеева, В. П. Мурыгина // Биосфера: междисциплинарный научный и прикладной журнал. - 2015. № 7. - С. 199-208.

13. Янин, Е.П. Ремедиация территорий, загрязненных химическими элементами: общие подходы, правовые аспекты, основные способы (зарубежный опыт) / Е. П. Янин // Проблемы окружающей среды и природных ресурсов. - 2014. - № 3. - С. 3-105.

14. Stalpers, J. A. Identification of wood-inhabitinq Aphyllophorales in pure culture // Bearn: Stul. Mycol. - 1978. - № 16. - 248 p.

15. Suki, C. Croan Conversion of conifer wastesinto edible and medicinal mushrooms / C. Croan Suki // Forest products journal. - 2004. - V. 54. - № 2. - P. 68-76.

16. Muller, H.W. Effect of phenolic compounds on cellulose degradation by same white-rot basidiomycetes /H. W. Muller, Trosch., K. D. Kulbe // FEMS Microbiol. Letters. - 1988. - V. 49. - № 1. - P. 87-93. 
UDC $631.45+635.8$

DOI: 10.36461/NP.2019.52.3.003

\section{STUDIES OF THE POSSIBILITY OF USING MUSHROOM WASTE IN BIOREMEDIATION OF AGRICULTURAL SOILS}

G. V. Ilyina, Doctor of Biological Sciences, professor; S. A. Sashenkova, Candidate of Biological Sciences, assistant-professor; D. Yu. Ilyin, Candidate of Biological Sciences, assistant-professor

Federal State Budgetary Educational Institution of Higher Education «Penza State Agrarian University», Russia, t. (8412) 62-81-51, e-mail: g-ilyina@yandex.ru

The paper considers the possibilities of using organic substrates after cultivation mycelial cultures of xylotrophic basidiomycetes for bioremediation of soils contaminated with polyphenolic compounds and heavy metals. A $0.9-3$-fold decrease in the integral soil toxicity indicator under the influence of mycelial-substrate complexes (mushroom cultivation and biotechnology waste) was shown. The dynamics of the humus content in soil samples as a result of introducing oyster mushrooms (Pleurotus ostreatus) as a fertilizer was studied. It was found that the content of humus in the experimental variants increased by $0.08-0.14 \%$. At the same time, the use of mushroom cultivation waste as fertilizers made it possible to increase the yield of spring wheat «Tulaykovskaya 10 » by $10.7-29.5 \%$.

Key words: bioremediation of soils, xylotrophic basidiomycetes, mycelial cultures, mushroom waste, integral toxicity.

\section{References:}

1. Biological environmental control: bioindication and bioassay: a training manual for students of institutes of higher education / O. P. Melekhova, E. I. Sarapultseva, T. I. Evseeva [et al.] - 3rd ed. - Moscow: Academiya, 2010. - 288 p.

2. GOST 28168-89. Soils. Sample selection. [Electronic resource] URL: http://docs. cntd. ru/document/gost-28168-89 (accessed September 26, 19)

3. Domracheva, L. I. The use of organisms and biosystems in the remediation of territories / L. I. Domracheva // Theoretical and Applied Ecology. - 2009 - No. 4. - p. 4-16.

4. Dospekhov, B. A. Methods of field experience / B. A. Dospekhov. - Moscow: Agropromizdat, 1985.-- $351 \mathrm{p}$.

5. Danilyak, N. I. Enzymatic systems of higher basidiomecetes / N. I. Danilyak, V. D. Semichaevsky, L. G. Dudchenko. - Kiev: Naukova Dumka, 1989.-- 279 p.

6. Kachmazov, D. G. Bioremediation of contaminated soils / D. G. Kachmazov // International Research Journal. - 2017 - No. 12 (66), - 3. - p. 107-109. [Electronic resource] URL: https://researchjournal. org/agriculture (accessed September 26, 19)

7. Kulikova, N. A. The use of basidiomycetes in technologies for processing and utilization of technogenic wastes: fundamental and applied aspects (review) / N. A. Kulikova, O. I. Klein, E. V. Stepanova, I. V. Korolyova // Applied Biochemistry and Microbiology. - 2011. - V. 47. No. 6. - p. 619-634.

8. PND F T 16.1: 2.3: 3.8-04. Quantitative chemical analysis of soils. [Electronic resource] URL: http://docs. cntd. ru/document/1200082146 (accessed September 26, 19)

9. PND F T 14.1: 2: 3: 4.11-04. Toxicological analysis methods. [Electronic resource] URL: https://files. stroyinf. ru/Data2/1/4293767/4293767837 htm (accessed September 26, 19)

10. FR.1.39.2007.03222, PND F T 14.1: 2: 4.12-06. Biological control methods. [Electronic resource] URL: https://files. stroyinf. ru/Data2/1/4293842/4293842234. htm (accessed September 26, 19)

11. Shvetsova, LK. Humus state and nitrogen fund of the main types of soils with prolonged use of fertilizers: abstract of the dissertation of the doctor of biological sciences / L. K. Shvetsova - Moscow, 1988 - 48 p.

12. Yankevich, M. I. Soil bioremediation: yesterday, today, tomorrow / M. I. Yankevich, V. V. Khadeeva, V. P. Murygina // Biosphere: an interdisciplinary scientific and applied journal. - 2015. - No. 7. p. 199-208.

13. Yanin, E. P. Remediation of territories contaminated with chemical elements: general approaches, legal aspects, basic methods (foreign experience) / E. P. Yanin // Problemy okruzhayushchej sredy i prirodnyh resursov. - 2014. - No. 3. - P. 3-105.

14. Stalpers, J. A. Identification of wood-inhabitinq Aphyllophorales in pure culture // Bearn: Stul. Mycol. - 1978. - № 16. - 248 p.

15. Suki, C. Croan Conversion of conifer wastesinto edible and medicinal mushrooms / C. Croan Suki // Forest products journal. - 2004. - V. 54. - № 2. - P. 68-76.

16. Muller, H.W. Effect of phenolic compounds on cellulose degradation by same white-rot basidiomycetes /H. W. Muller, Trosch., K. D. Kulbe // FEMS Microbiol. Letters. - 1988. - V. 49. - № 1. P. 87-93. 